\title{
I 05 MR imaging sequences and clinical validation of a technique for respiratory motion correction in XMR-guided cardiac catheterisations
}

\author{
Andrew P King*1, Redha Boubertakh ${ }^{1}$, Kawal S Rhode ${ }^{1}$, Ying-Liang Ma ${ }^{1}$, \\ Phani Chinchapatnam², Gang Gao ${ }^{2}$, Tarinee Tangcharoen ${ }^{1}$, Matthew Ginks ${ }^{1}$, \\ David J Hawkes ${ }^{2}$, Reza Razavi ${ }^{1}$ and Tobias Schaeffter ${ }^{1}$
}

Address: ${ }^{1}$ Kings College London, London, UK and ${ }^{2}$ University College London, London, UK

* Corresponding author

from I I th Annual SCMR Scientific Sessions

Los Angeles, CA, USA. I-3 February 2008

Published: 22 October 2008

Journal of Cardiovascular Magnetic Resonance 2008, I0(Suppl I):A230 doi:10.I I86/I532-429X-I0-SI-A230

This abstract is available from: http://jcmr-online.com/content//0/SI/A230

(c) 2008 King et al; licensee BioMed Central Ltd.

\begin{abstract}
Introduction
We have previously developed an augmented reality system that provides an anatomical roadmap derived from MR imaging that is continually aligned to X-ray fluoroscopy images in the XMR hybrid imaging environment [1]. We have used this system to guide cardiac catheterisation for more than 50 clinical cases. This system provides an accuracy of $2 \mathrm{~mm}$, but respiratory motion introduces errors that are typically much greater than this. In this abstract, we describe a novel technique for correcting for respiratory motion using a patient-specific motion model derived from MR imaging. Validation was performed on four volunteer and three patient datasets.
\end{abstract}

\section{Methods}

Two MR imaging sequences are required to form the motion model: a 3-D high-resolution MRI for the anatomy and a dynamic near real-time scan to determine the respiratory motion. For the high-resolution dataset, a free breathing 3-D balanced TFE sequence is used, which is acquired at diastole during end-expiration. For the volunteers three additional high-resolution volumes were acquired at different respiratory positions for validation (typically, 120 slices, $\mathrm{TR}=4.4 \mathrm{~ms}, \mathrm{TE}=2.2 \mathrm{~ms}$, flip-angle $=90^{\circ}$, acquired voxel size $2.19 \times 2.19 \times 2.74 \mathrm{~mm}^{3}$, reconstructed to $1.37 \times 1.37 \times 1.37 \mathrm{~mm}^{3}, 256 \times 256$ matrix). Two different dynamic scan sequences were applied, which use respiratory navigators immediately before and after acquisition:

\section{Single volume}

-D TFEPI, typically, 20 slices, TR $=11.75 \mathrm{~ms}, \mathrm{TE}=5.84 \mathrm{~ms}$, flip-angle $=20^{\circ}$, acquired voxel size $3.81 \times 4.27 \times 8.0$ $\mathrm{mm}^{3}$, reconstructed to $2.22 \times 2.22 \times 4.0 \mathrm{~mm}^{3}, 144 \times 144$ matrix, 100 dynamics;

\section{2 sagittal slices}

Multislice balanced TFE, typically, TR $=2.74 \mathrm{~ms}, \mathrm{TE}=1.37$ $\mathrm{ms}$, flip-angle $=60^{\circ}$, acquired voxel size $1.78 \times 1.75 \times 8.0$ $\mathrm{mm}^{3}$, reconstructed to $1.09 \times 1.09 \times 8.0 \mathrm{~mm}^{3}, 320 \times 320$ matrix, 100 dynamics. The 2 sagittal slice sequence was tested because in our experience the dominant cardiac respiratory motion parameters are the inferior-superior and anterior-posterior translations, the inferior-superior scaling, and the lateral axis rotation. All of these parameters can be more accurately estimated from high-resolution sagittal slices.

The motion model is constructed by registering each dynamic acquisition to the high-resolution volume using an affine intensity-based algorithm. The affine registration parameters are modelled using polynomial functions of the diaphragm position[2]. We model inspiration and expiration phases separately, constraining the curves so 
that they meet at the extremes of inspiration and expiration. Figure 1 shows sample parameter plots from two volunteers.

A heart model was constructed from the 3-D high-resolution scan and the motion model. In order to use this model within the augmented reality system, the diaphragm position is automatically determined from X-ray fluoroscopy images. The cardiac roadmap is then updated using the model. We gate the X-ray images at diastole by synchronising X-ray image acquisition with the electrocardiogram signal.

\section{Results}

In the volunteer datasets errors were computed by using the model to predict the locations of landmarks in the three additional high-resolution MR images. Accuracy was 2-4 $\mathrm{mm}$, with the single volume dynamic sequence showing slightly higher errors. For the clinical cases, 2-D errors were assessed by overlaying a rendering of a vessel onto Xray images that showed a catheter positioned inside the vessel. For Patient A the error was reduced from $13.3 \mathrm{~mm}$ to $2.8 \mathrm{~mm}$, for Patient B from $5.1 \mathrm{~mm}$ to $3.9 \mathrm{~mm}$, and for Patient $\mathrm{C}$ from $7.5 \mathrm{~mm}$ to $2.2 \mathrm{~mm}$. Figure 2 shows the images used for Patient A.

\section{Discussion}

We have demonstrated the construction of a patient-specific cardiac respiratory motion model from MRI data and its application to an augmented reality system for guiding cardiac catheterisations. We anticipate that such models will have widespread applications that include roadmap-

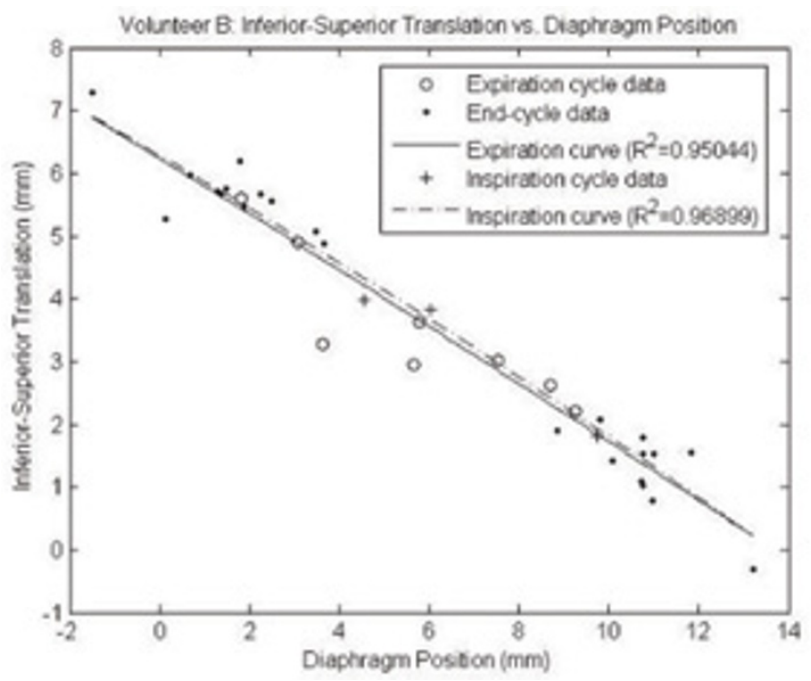

Figure I

Sample parameter plots used to form motion model. ping during MR-guided interventions and also MR image acquisition.

\section{References}

I. Rhode, et al.: TMI 2005, 24(I I ): |428- | 440.

2. Manke, et al:: TMI 2002, 2 I(9):I | 32-I I4I.

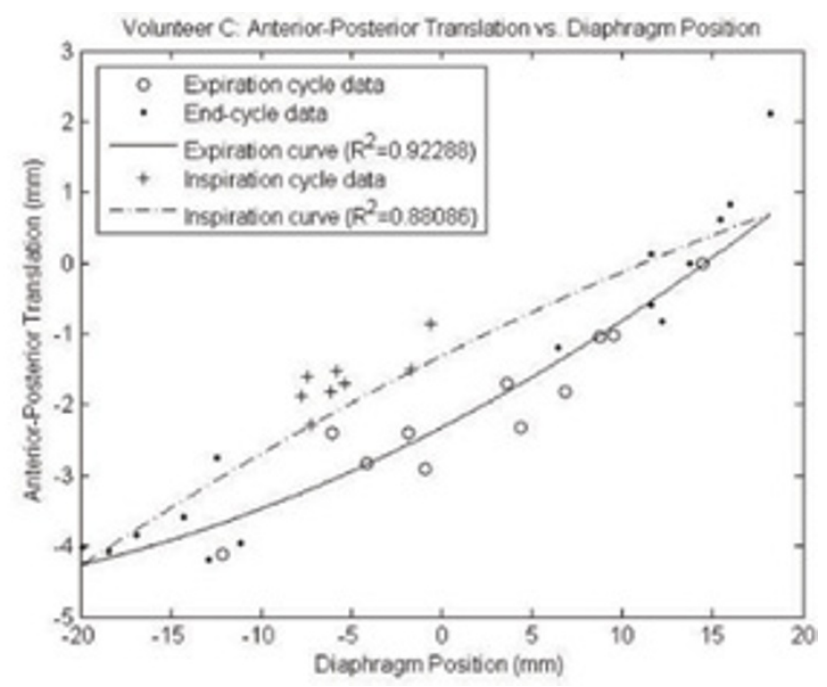



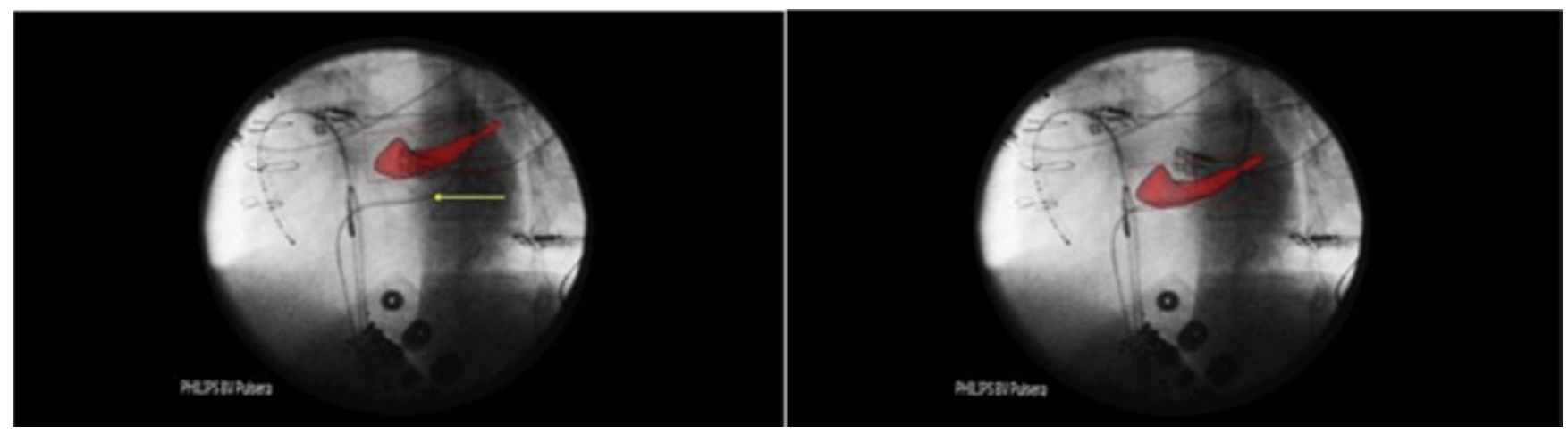

Figure 2

MRI-derived overlay of the coronary sinus onto X-ray image showing a coronary sinus catheter (indicated by arrow) - before (top) and after (bottom) motion correction.

Publish with Biomed Central and every scientist can read your work free of charge

"BioMed Central will be the most significant development for disseminating the results of biomedical research in our lifetime. " Sir Paul Nurse, Cancer Research UK

Your research papers will be:

- available free of charge to the entire biomedical community

- peer reviewed and published immediately upon acceptance

- cited in PubMed and archived on PubMed Central

- yours - you keep the copyright
BioMedcentral 